\title{
Article
}

\section{Physical Ergonomic Improvement and Safe Design of an Assembly Workstation through Collaborative Robotics}

\author{
Ana Colim ${ }^{1, * \mathbb{C}}$, Carlos Faria $^{1}$, João Cunha ${ }^{1}$, João Oliveira ${ }^{1}\left(\mathbb{D}\right.$, Nuno Sousa $^{2}$ and Luís A. Rocha ${ }^{1} \mathbb{C}$ \\ 1 Associação Laboratório Colaborativo em Transformação Digital-DTx Colab, 4800-058 Guimarães, Portugal; \\ carlos.faria@dtx-colab.pt (C.F.); joao.cunha@dtx-colab.pt (J.C.); joao.oliveira@dtx-colab.pt (J.O.); \\ luis.rocha@dtx-colab.pt (L.A.R.) \\ 2 Human Engineering, Production and Systems Department, University of Minho, \\ 4800-058 Guimarães, Portugal; nuno.sousa@dps.uminho.pt \\ * Correspondence: ana.colim@dtx-colab.pt
}

Citation: Colim, A.; Faria, C.; Cunha, J.; Oliveira, J.; Sousa, N.; Rocha, L.A. Physical Ergonomic Improvement and Safe Design of an Assembly Workstation through Collaborative Robotics. Safety 2021, 7, 14. https://doi.org/10.3390/safety 7010014

Received: 21 December 2020

Accepted: 8 February 2021

Published: 18 February 2021

Publisher's Note: MDPI stays neutral with regard to jurisdictional claims in published maps and institutional affiliations.

Copyright: (c) 2021 by the authors. Licensee MDPI, Basel, Switzerland. This article is an open access article distributed under the terms and conditions of the Creative Commons Attribution (CC BY) license (https:// creativecommons.org/licenses/by/ $4.0 /)$.

\begin{abstract}
One of the key interesting features of collaborative robotic applications is the potential to lighten the worker workload and potentiate better working conditions. Moreover, developing robotics applications that meets ergonomic criteria is not always a straightforward endeavor. We propose a framework to guide the safe design and conceptualization of ergonomic-driven collaborative robotics workstations. A multi-disciplinary approach involving robotics and ergonomics and human factors shaped this methodology that leads future engineers through the digital transformation of a manual assembly (with repetitive and hazardous operations) to a hybrid workstation, focusing on the physical ergonomic improvement. The framework follows four main steps, (i) the characterization of the initial condition, (ii) the risk assessment, (iii) the definition of requirements for a safe design, and (iv) the conceptualization of the hybrid workstation with all the normative implications it entails. We applied this methodology to a case study in an assembly workstation of a furniture manufacturing company. Results show that the methodology adopted sets an adequate foundation to accelerate the design and development of new human-centered collaborative robotic workstations.
\end{abstract}

Keywords: human-robot collaboration; safe design; risk assessment; safety standardization; physical ergonomics; work-related musculoskeletal disorders; manufacturing

\section{Introduction}

In industrial contexts with a manufacturing component, the workforce is exposed to several occupational risk factors [1]. The incidence of work-related musculoskeletal disorders (WMSD) is a principal occupational health problem and a leading cause of occupational absenteeism and decreased productivity [2].

To reduce the human workload and, eventually, the WMSD risk, collaborative manufacturing with physical human-robot collaboration (HRC) has been considered [3,4]. The use of industrial cobots, i.e., collaborative robots, in manufacturing assembly lines, has been pointed out as an innovative solution to reduce ergonomic concerns that result from on-the-job physical and cognitive overload while improving workplace safety, quality, and productivity [5].

The collaborative work-cell, also known as a hybrid work-cell, can be defined as a bounded connected space where the human and the robotic system interact in a joint task. Contrary to more traditional robotic applications, where there is a clear temporospatial separation between the worker and the machine domain, in a collaborative context, by definition, these spaces overlap. The collaborative philosophy has found its way into multiple industrial applications-handling, assembly, inspection, among others-comprehending diverse levels of HRC However, there is no consensus about the categorization of the levels of HRC [6-8]. Different terms, such as coexistence, cooperation, or collaboration, have been used to distinguish the type of interaction but none without their subjectivity. Cesta 
et al. [9] proposed four degrees of HRC based on the workspace time and space separation (Figure 1). Independent scenarios occur when the robot and the human-coworker operate on separate workpieces and different processes. In simultaneous cases, the robot and operator work on the same workpiece but in separate processes. In the sequential scenario, the robot and the operator work on the same workpiece at distinct but time-dependent processes, i.e., one process can only start when the previous has finished. Finally, the supportive scenario includes the cases where the robot and operator work together in the same process and workpiece simultaneously.
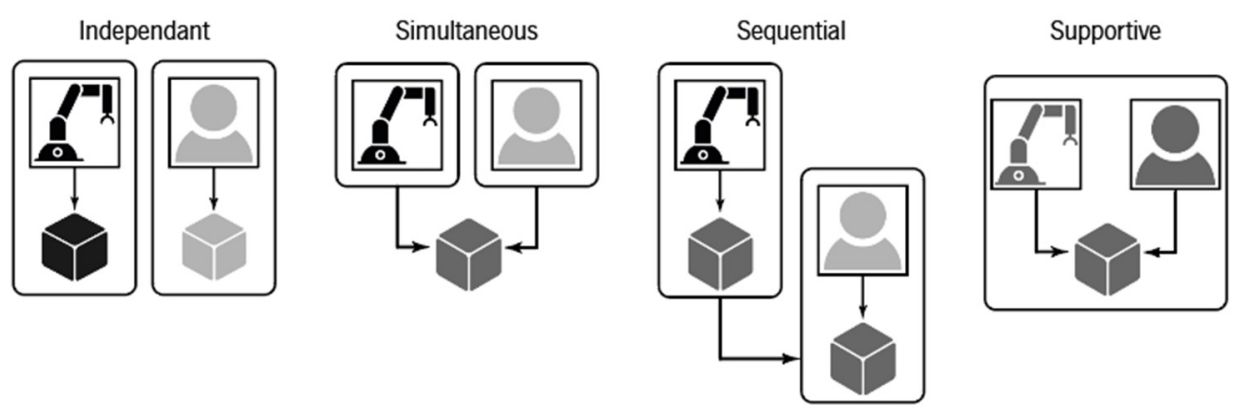

Figure 1. Different levels of HRC.

In collaborative solutions, robots operate in a shared workspace with operators, which allows a versatile collaboration [10]. At the same time, human safety remains the most critical topic in HRC, being currently addressed during the project design phase [11]. The most recent technical specification about HRC, the ISO/TS 15066:2016 [12], attempts to establish a baseline on safeguarding workers from accidents and the management of legal consequences. Furthermore, standardization related to the risk assessment in terms of occupational safety, IEC 31010:2019 [13]; ergonomic assessment, such as ISO/TR 12295:2014 [14]; and anthropometric requirements for the design of workstations at machinery, ISO 14738:2002 [15], provided requirements and recommendations that should be considered in all work settings, including those with HRC.

Several studies centered on the conceptualization and development of technologies that support HRC emerged in the last years [10]. There is, however, a lack of empirical studies showing how manufacturing industries are implementing this type of technology [16]. Real-industry developments and implementations of HRC constitute an emergent research challenge [17]. On top of that, attention to human factors has been particularly sparse [18]. Thus, it becomes fundamental to create human-centered approaches to support the implementation of HRC in industrial contexts. To achieve that, human factors must be a central point in all development phases of these new work systems, from their design, until their implementation and validation. The current study aims to contribute to these research challenges. Previous studies present important guidelines and frameworks related to the design of HRC workstations $[11,19,20]$. Most of them are based on hierarchical task analysis to define task allocation.

In this paper, results from the cooperation between a research laboratory and a furniture manufacturing company are presented and discussed. This cooperation focused on a real and specific problem related to a manual assembly workstation. The main purpose of this work was to create a new assembly workstation capable of simultaneously improving workstation safety and ergonomics and accommodate workers with musculoskeletal problems. Concerning the design of this workstation, we elaborated a staged framework that could guide developers and integrators through the process of the design and conceptualization of human-centered cobot workstations. The framework was defined by the research team, and it was applied in a real-industry case study, considering standardization and legal requirements, safety and physical ergonomic criteria. 


\section{Method and Materials}

A multi-disciplinary team of experts on ergonomics and human factors (E\&HF) and robotics, industrial practitioners, and workers selected an assembly workstation as a case study for this collaborative robotics project. The decision was based on the prevalence of workers' complaints and WMSD registered by the department of occupational health.

To design and develop the new collaborative robotics workstation, we applied four methodological stages, as follows:

(i) Characterization of the initial condition/case study-assembly workstation with repetitive manual handling operations (MHO);

(ii) Risk assessment process specifically defined according to the case study;

(iii) Requirements definition according to safety and ergonomic principles;

(iv) Development of concepts for the design of hybrid workstation.

Meetings with the workers were conducted during all the design stages of the project, to achieve a comprehensive and detailed characterization of the workstation. Furthermore, previous studies, legal requirements and European standards related to collaborative workstations were consulted, being transversal to all design stages. The methodological options are described and justified along the following subsections.

To summarize this design approach, a framework for the safe design of the HRC workstation was conceptualized and applied in this real-industry case study. This framework helps to synthesize and to interrelate the main recommendations and guidelines that should be considered during this design phase. This contribution is especially important since there are several standards and previous studies that must be considered.

Figure 2 presents the framework that describes the entire design process for the hybrid workstation, integrating E\&HF criteria and safety requirements for collaborative robotics systems. In addition, this methodology considers the need to reassess risks and redefine requirements as the collaborative solution takes shape and new technologies are included.

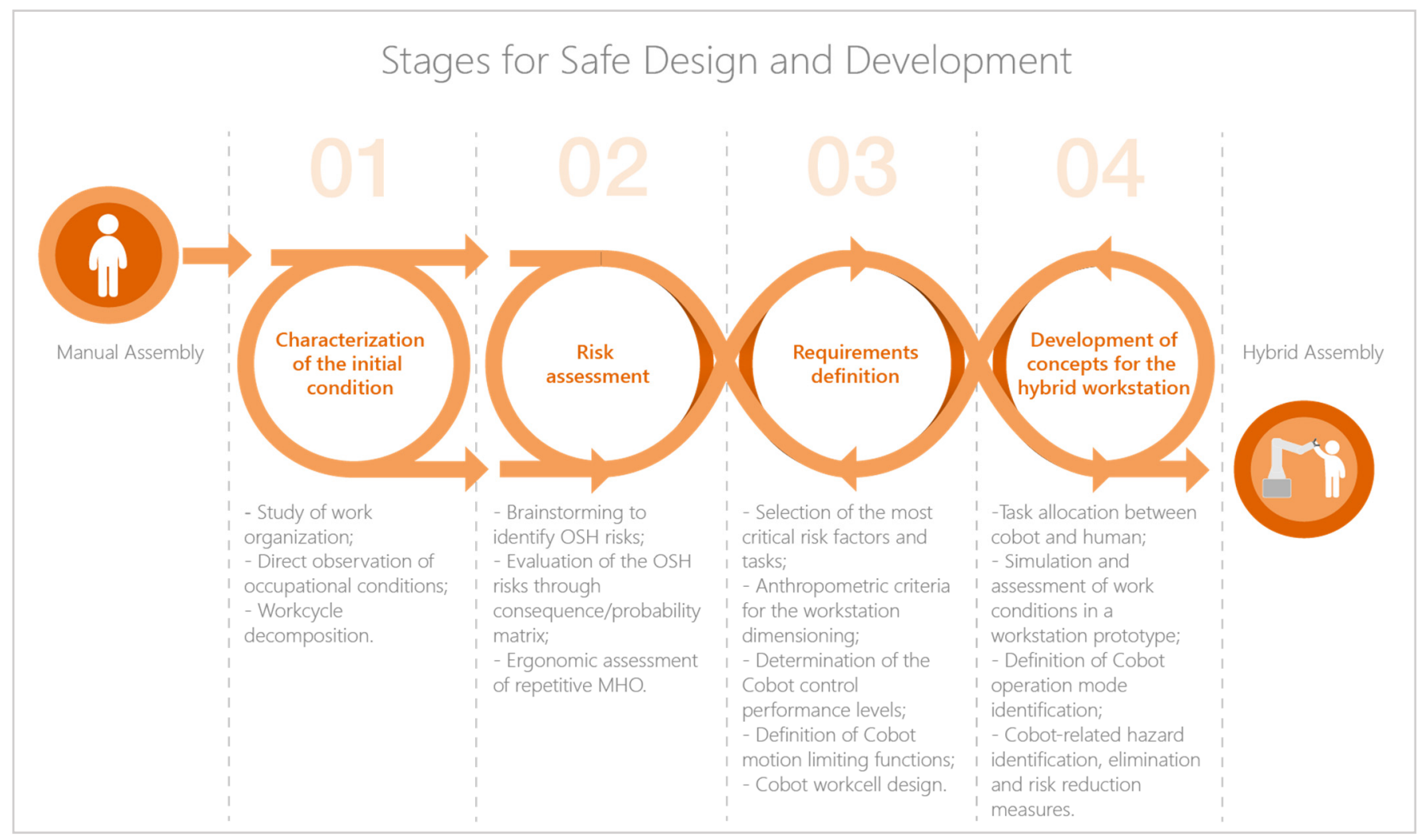

Figure 2. Framework adopted in the case study. 
In the furniture manufacturing company, the workstation under study had 8 allocated workers with WMSD problems diagnosed. These workers are all female with $49.9( \pm 7.7)$ years old, and they have $10.9( \pm 0.4)$ years of work experience in the assembly section. The eight workers reported one or more musculoskeletal problems (such as carpal tunnel syndrome, disc herniation, or tendinitis).

The studied work activity consists of a manual assembly with medium density fiberboards (MDF) frames where different MDF components are glued. The glue is applied with a hot glue gun activated by a finger trigger. The tasks are the following:

(i) Task 1 (T1): reach for the stripes from a pallet and place them in the assembly workbench;

(ii) T2: Pick the blocks (small MDF pieces) from a box;

(iii) T3: Reach for the glue gun and apply glue to the blocks;

(iv) T4: Glue the blocks to the stripes;

(v) T5: Dislodge the stripes;

(vi) T6: Transfer the semi-product to the pallet.

Workers performed several repetitive upper limb tasks with variable force requirements and postures (as demonstrated in Figure 3).
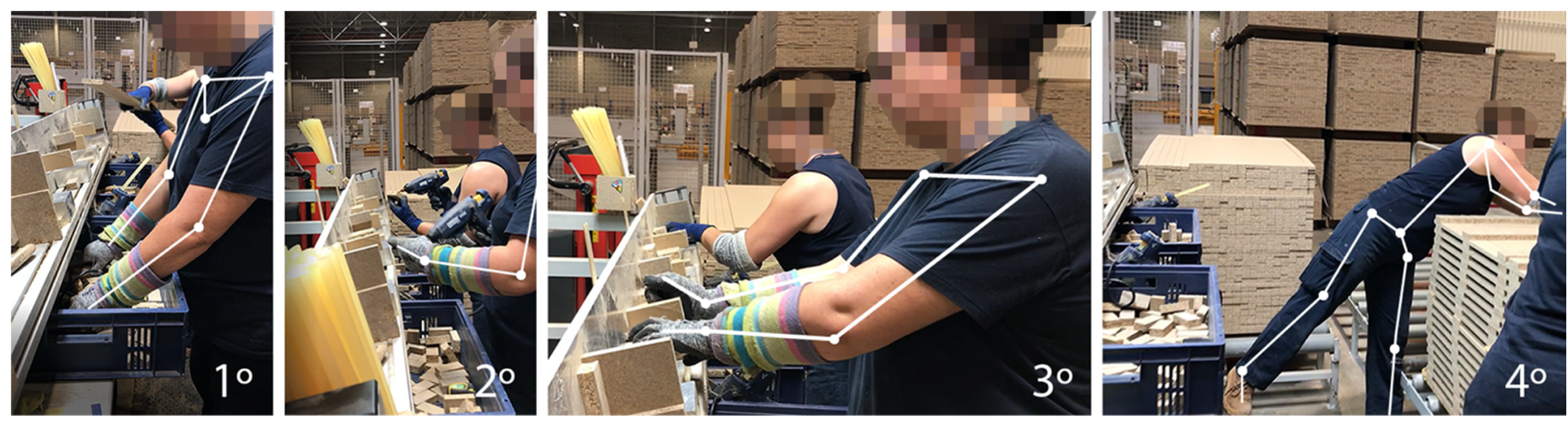

Figure 3. Workers postures during the assembly work cycle.

\subsection{Characterization of the Initial Condition}

Visits were carried out to collect information on work organization (such as work shift duration, breaks), physical and mental requirements, workers' complaints and WMSD, working conditions, tasks performed, dangerous conditions, occupational risks identified, and preventive measures implemented. Photographs and videos of the workers performing their tasks were also registered, with the proper consent from the considered workers.

The work cycle was decomposed and a time study with a confidence level of, at least, $90 \%$ and a superior error limit error of $\pm 5 \%$ was developed, observing two workers along 25 work cycles.

Workers participated in the study voluntarily. All participants signed an Informed Consent Term in agreement with the Committee of Ethics for Research in Social and Humans Sciences of the University of Minho (approval number CEICSH 095/2019), and in agreement with the Declaration of Helsinki.

\subsection{Risk Assessment}

According to the ISO 31000:2018-“"Risk Management-Guidelines" [21], the risk assessment should be conducted systematically and collaboratively, drawing on the knowledge and views of the different stakeholders. Therefore, the risk assessment was carried out by direct observation and with the active participation of the workers and production supervisors. This approach follows the recommendations present in the international standard IEC 31010:2019_ “Risk Management-Risk Assessment Techniques” [13]. Initially, 
conducting meetings with workers allowed the realization of brainstorming to identify the principal risks of the manual assembly. Then, a technique for consequence/probability matrix to analyze and evaluate the risks was selected. During company visits, other relevant data were collected to fill out a matrix to calculate the risk level. The risk assessment was based on the William Fine method [22], which relies on equations that express the control of risks and the rationale behind the decisions on preventive measures. It attributes a degree of risk that is calculated based on three factors: (i) the probability of the accident occurring $\left(F_{P}\right)$; (ii) the degree of exposure to the risk $\left(F_{E}\right)$; (iii) the consequences of the accident $\left(F_{C}\right)$. The risk score $\left(R_{S}\right)$ is determined using:

$$
R_{S}=F_{P} \times F_{E} \times F_{C} .
$$

The $R_{S}$ (or risk level) allows the establishment of a prioritization of the actions to be performed. According to the William Fine method [22], the risk level is categorized in four levels, namely:

(i) Risk level I (with a final score equal to or more than 250 points): Immediate correction is required, activity should be stopped until the hazard is reduced;

(ii) Risk level II (scores between 90 to 250 points): the intervention is urgent, requiring attention as soon as possible;

(iii) Risk level III (scores between 18 to 90 points): Hazard should be eliminated without delay, but the situation is not an emergency;

(iv) Risk level IV (scores equal or less than 18 points): Hazard should be addressed when time is given.

Therefore, the William Fine results will identify the most critical risks. In addition, the revised strain index (RSI) [23] was applied for the musculoskeletal risk assessment. The RSI is especially fit for the distal upper limbs [24] and indicated for jobs with multiple manual operations, as indicated by the ISO 12295:2014 [14]. The final SI score corresponds to the product of multipliers estimated according to the exposure to risk factors. The risk factors are the following: the intensity of exertion (force), exertions per minute (frequency), duration per exertion, hand/wrist posture, duration of task per day. An ordinal rating is assigned following the exposure conditions for each factor, then a multiplier value corresponding to the rating is obtained.

In this assessment, different work cycles were observed, and 40 postures were evaluated. For each task, the musculoskeletal risk level was defined according to the mean RSI score.

For each task, to support the risk assessment, the workers expressed their subjective perception of physical overload. This self-reported physical exertion was evaluated with "Category Ratio-10" (CR-10) [25]. Previous studies [26,27] supported that this psychophysical scale is a valid and reliable tool for assessing the exertion self-assessment by workers exposed to WMSD risk factors during manual tasks. Based on this evidence, the CR-10 scale was applied to support the RSI application (in the measurement of the multiplier of the intensity of effort) and to identify the most critical tasks for the workers.

\subsection{Requirements Definition}

Considering the manual workstation, the previous risk assessment phase allowed the identification of the main occupational safety and health $(\mathrm{OSH})$ risk factors and the selection of the most critical tasks in terms of musculoskeletal overload.

In the E\&HF field, the ISO 9241:2010 [28] is a multi-part standard covering "Ergonomics of human-system interaction". Part 9241-210 [28] provides requirements and recommendations for human-centered design for computerized and interactive systems. According to the mentioned standard, the design of these work systems should include the following phases: (i) understand and specify the context of use; (ii) define the user/worker requirements; (iii) design solutions to meet user requirements/needs; and (iv) evaluate design solutions [28], as followed in the current study. Considering the importance of an- 
thropometric data, namely in what concerns the design of workstations with an important manual component, the ergonomic recommendations should consider anthropometric data, as recommended by the ISO 14738:2002_ “Safety of Machinery-Anthropometric Requirements for the Design of Workstations at Machinery" [15]. To achieve an adequate design for the final real users, we considered the validated database of anthropometric measures for the adult Portuguese population [29]. For this purpose, the following methodological steps were applied: (i) identification of the relevant dimensions in the workstation (e.g., assembly workbench height); (ii) identification of the relevant anthropometric dimensions (e.g., elbows' height is used as a reference in the definition of the manual workbench height); (iii) identification of the criteria to be used, according to ergonomic recommendations (e.g., hands movements must not exceed the shoulders height and joints in a neutral position [29]. In this stage, we considered the anthropometric dimensions to cover $95 \%$ of the female population. For the dimensions measured in relation to the ground, an increment of $25 \mathrm{~mm}$ was considered, corresponding to the correction of footwear.

Based on the identification of the main OSH risk factors, the designer of the cobot system solution defines how to intervene and what is the most adequate solution for the new process (refer to Section 2.4). In the case of the design and development of the cobot system, the requirements' definition succeeds the workstation conceptualization because different solutions introduce variate requirements.

When the cobot system is outlined, one should start by consulting the legal requirements that affect the proposed solution. The legal requirements vary depending on the jurisdiction country. In Europe, for example, the European Union dictates the Machinery Directive (2006/42/EC) [30] that is upheld in each member state by its own set of law decrees. Faria et al. [31] list the European directives as well as the harmonized EN ISO standards required to achieve a conformant cobot system.

At this design phase, the system developer/integrator shall conduct a risk assessment to guarantee that it meets the essential health and safety requirements from Annex I of the Machinery Directive (2006/42/EC). This verification can be supplemented by the Annex G of the ISO 10218-2 standard-means of verification of the safety requirements and measures.

\subsection{Development of Concepts for the Hybrid Workstation}

The conceptualization of the hybrid workstation draws from the previous framework phases to answer two important questions, how to intervene, and which solution should be implemented. The answers to these questions are often intertwined since the type of intervention depends on the feasibility of the technological solution, which consequently influences the extent and depth of the digital transformative process. There are three main areas of intervention when considering the hybrid workstation: (i) human-robot task allocation, (ii) new technological equipment, and (iii) adjustment of the workstation.

First, the task allocation between worker and robot was considered. The initial workstation characterization and risk assessment set the basis on which a draft of the new work cell requirements can be established. These requirements will prioritize addressing the most demanding tasks, which will influence the task allocation between worker and robot. Here, the transformation feasibility and technological readiness-levels act as a counterweight to balance which tasks are performed by whom. Upon selecting the cobot tasks as well as the collaborative operation mode, one can support itself on the EN ISO 10218-2 [32] and ISO/TS 15066 [12] to identify the task-related hazards. Annex A in EN ISO 10218-2 lists the most significant hazards for collaborative robotic applications, and Annex A in ISO/TS 15066 identifies the permissible limits for quasi-static and transient contact between robot and worker. The same standards point out hazard elimination and risk reduction measures for each of the four collaborative operation modes: safety-rated monitored stop (SMS), hand-guiding (HG), speed and separation monitoring (SSM), and power and force limiting (PFL) (refer to Section 2.3). The definition of cobot intervention has repercussions on phase 3-requirements definition, of this framework (see Section 3). 
Second, the new technological equipment is primarily dictated by the cobot tasks at hand and filtered to meet the expected safety requirements and measures. The risk assessment of a robotic system, as a machine, comprehends not only the robot but also the attached equipment (e.g., end-effector, structures) as well as carried cargo. The success of cobot has elicited the creation of "collaborative end-effectors", i.e., end-effectors that favor non-sharp geometries and whose actuation forces fall within the maximum pressure and force values defined in the ISO/TS 15066 technical specification. Selecting technology compliant with the harmonized standards accelerates the certification process of an integrated solution. Whenever accessory technology that cannot safely share the workspace with workers is deemed necessary, adequate risk assessment methodologies and consequent risk mitigation approaches are necessary, e.g., through physical safeguards (refer to ISO 13857 [33]).

Finally, the transformation of the workstation should consider the anthropometric data of the workers for their new task allocation, as well as the introduction of the cobot system with all the integrated technology. For the dimensioning of the workstation, the software Jack-Siemens ${ }^{\circledR}$ (trial version [34]) was applied to test different heights within the interval of values defined by the anthropometric requirements (defined in the previous phase). The mentioned software allows human modelling according to anthropometric data, the creation of virtual work environments, and possesses many ergonomic analytical tools [20]. In this case, the height workbench and the postures were assessed with the Rapid Upper Limb Assessment (RULA) [35]. The RULA [35] is one of the most well-known methods for musculoskeletal assessment considering the joint positions of the upper limbs, neck and trunk (body parts recruited in the assembly tasks studied) [36-38]. Its application involves the assessment of the postures adopted by the worker, as well as the forces exerted, the repetitiveness of movements, and external loads. With this simulation and assessment, the height for the workbench (or the principal hands' location) was defined.

To test these ergonomic requirements, a prototype of the workbench was created in our laboratory. This prototype enabled the testing of multiple positions for the assembly of the workpieces. Two assembly workers reproduced their respective work-cycles with the different workpiece positions, and their perceptions (of their actions) were collected using a Visual Analog Scale (VAS) (Figure 4).

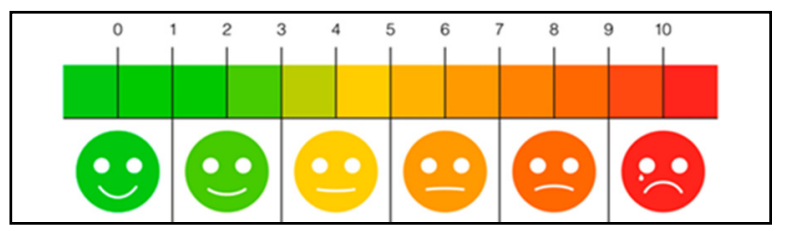

Figure 4. VAS applied in order to assess the workers' perceptions about discomfort.

The musculoskeletal risk was assessed for the conditions tested by XSens ${ }^{\circledR}$ technology. The Xsens MTx sensors applied in this study incorporate 3D gyroscopes, accelerometers, and magnetometers which have the potential to be used for assessing human movement in various environments with good accuracy [39-41]. This system captures the motion data (orientation, position, movement, and center of mass of the different parts of the body) in real-time, at a frequency of $120 \mathrm{~Hz}$.

For data collection, 11 inertial sensors were fixed on different body landmarks (Figure 5). These sensors tracked the motion data during the predefined tasks. The raw data was collected and analyzed by the XSens MVN software version 2019.2.1. Then, it was exported in the mvnx format to be uploaded to the mvncloud.xsens.com. For each simulated workcycle, the RULA score was obtained with an algorithm (named RULA report) developed by Xsens ${ }^{\circledR}$, which integrates the kinematics data collected. This algorithm estimates the WMSD risk level for an entire work cycle, as well as for each frame selected. 


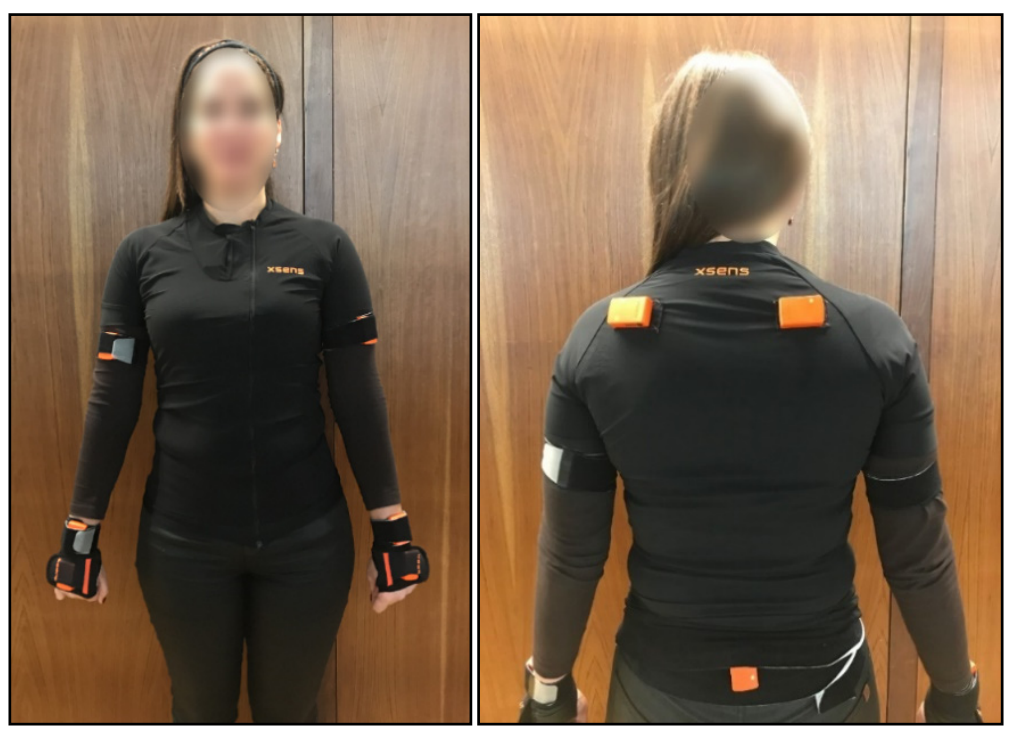

Figure 5. Participant with the 11 inertial sensors attached.

\section{Results and Discussion}

\subsection{Characterization of the Initial Condition and Risk Assessment}

Risks, estimated by the William Fine method [22] are summarized in Table 1. The risk assessment pointed out the five main risks in the current assembly workstation. With a lower score, there is the risk of collision with workspace objects (e.g., raw materials, roller conveyors). The preventive measures to improve the physical conditions and the layout of this area are the following: protect sharp edges and corners; signal the main obstacles; introduce a rotative table for the pallet; and mandatory use of personal protective equipment (PPE), such as gloves and footwear, for mechanical protection.

Table 1. Summary of the William Fine assessment.

\begin{tabular}{|c|c|c|}
\hline Risk & Consequence & Risk Level \\
\hline $\begin{array}{l}\text { Contact with fluids } \\
\text { at high temperatures }\end{array}$ & $\begin{array}{l}\text { Burns, ocular } \\
\text { injuries. }\end{array}$ & $\begin{array}{l}\text { I-Immediate correction required; activity should be } \\
\text { stopped until the hazard is reduced }\end{array}$ \\
\hline $\begin{array}{l}\text { Disrespect for } \\
\text { ergonomic principles }\end{array}$ & WMSD & $\begin{array}{l}\text { I-Immediate correction required; activity should be } \\
\text { stopped until the hazard is reduced. }\end{array}$ \\
\hline Noise exposure & Stress, fatigue. & $\begin{array}{l}\text { I-Immediate correction required; activity should be } \\
\text { stopped until the hazard is reduced. }\end{array}$ \\
\hline $\begin{array}{l}\text { Psychosocial (work } \\
\text { overload) }\end{array}$ & Stress, fatigue. & $\begin{array}{l}\text { I-Immediate correction required; activity should be } \\
\text { stopped until the hazard is reduced. }\end{array}$ \\
\hline $\begin{array}{c}\text { Collision with } \\
\text { obstacles or objects }\end{array}$ & $\begin{array}{l}\text { Hematoma, } \\
\text { trauma, cuts. }\end{array}$ & I-Urgent! Requires attention as soon as possible. \\
\hline
\end{tabular}

Regarding noise exposure, the workers use personal hearing protectors to mitigate the risk of noise-induced hearing loss. However, this exposure increases muscle tension, mental stress, and negatively impacts job performance by impairing the communication between workers [42]. Additionally, previous studies proved that workers do not always wear the protectors correctly and consistently, a factor that compromises a proper noise attenuation [43]. Thus, collective measures should be considered to reduce the overall noise level at the work floor such as machine maintenance or replacement of noisy machinery.

We recommend the implementation of brief and more frequent breaks, considering the psychosocial risk associated with highly repetitive work and work overload. The HRC could also attenuate this risk by diminishing the physical strain-induced to the workers. This technical solution could reduce risks related to the negligence of ergonomic principles 
and reduce the exposure to high-temperature fluids (combined with the mandatory use of PPE-thermal protection gloves). Collaborative manufacturing with physical Humanrobot task assignment has been proposed as one of the most favorable solutions to improve workplace conditions. Previous studies support this theory by presenting positive results in the reduction of the workload and the decrease of the WMSD risk $[3,4,11]$.

According to the ISO 6385:2016 [44], in a work system design, the formulation of goals/requirements has to include an ergonomic assessment to elicit human characteristics, which can be combined with technical specifications. This assessment is crucial to allocate workers and robot functions such that their collaboration can improve safety, human health and wellbeing as well as system performance [45]. Most of the assembly workers presented wrist-related musculoskeletal disorders (carpal tunnel syndrome). Consequently, we included methods focused on the wrist-hand system, such as RSI [24,46]. The RSI results—relative to the musculoskeletal risk assessment-are presented in Table 2, and the workers' perceived exertion is presented in Figure 6.

Table 2. Summary of the time study and RSI assessment (bold denotes the major final SI score).

\begin{tabular}{cccc}
\hline Task & Mean Time (sec) & RSI Mean Score & Meaning \\
\hline T1 & $3.87(0.13)$ & $1.9(0.1)$ & Safe \\
T2 & $6.23(0.35)$ & $6.6(1.1)$ & Safe \\
T3 & $4.24(0.76)$ & $\mathbf{1 2 . 3}(3.3)$ & Unsafe \\
T4 & $7.54(0.15)$ & $2.3(0.0)$ & Safe \\
T5 & $3.04(0.58)$ & $1.0(0.0)$ & Safe \\
T6 & $2.44(0.01)$ & $1.0(0.0)$ & Safe \\
\hline
\end{tabular}

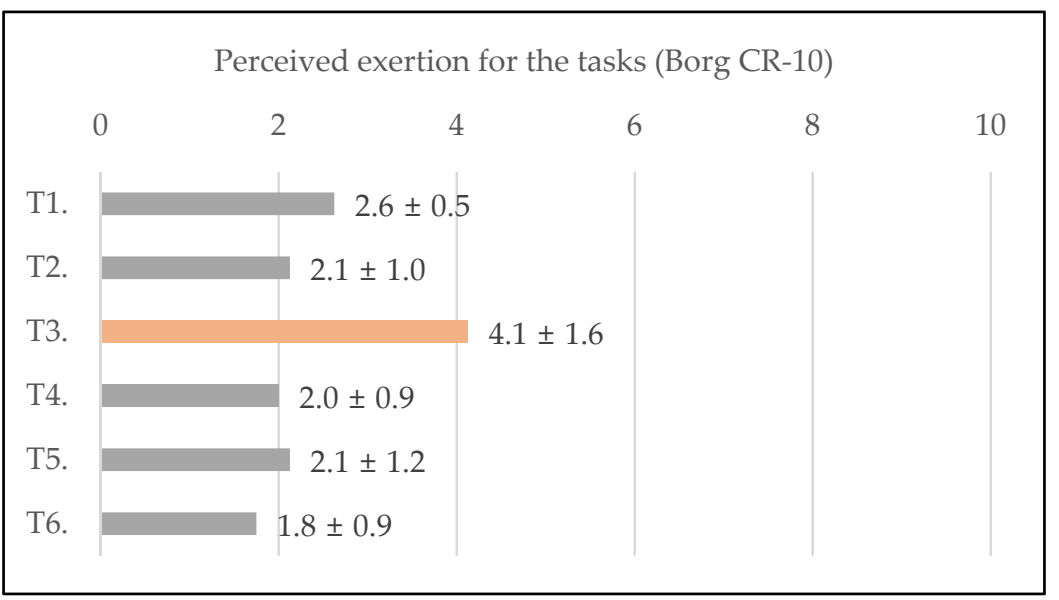

Figure 6. Perceived exertion (mean values \pm SD) across the tasks ( $n=8$ workers).

The RSI assessment pointed out a higher WMSD risk associated with Task 3 (apply glue to the blocks), mainly due to the task intensity. The workers also identify Task 3 as the most strenuous due to its repetitiveness (glue gun finger activation). The workers' perception of load and health disorders are relevant indicators of the workload [25]. Therefore, their opinions must be considered in the design of any new work systems.

\subsection{Requirements Definition}

From the ergonomic point of view, the height of a workbench for manual labor should be close to the neutral elbow position. The worker is in a neutral posture when his/her joints are aligned and near their midrange of motion. In these neutral/favorable positions, joints have higher force throughput and better control over the movements while reducing the stress-induced to the musculoskeletal system. For completeness, in an awkward posture, the joints are closer to their mechanical limits, and the recruited muscles and tendons are more contracted or elongated. 
In an awkward posture, a worker will expend more muscular energy to generate extra muscular tension and exert the same force when compared to executing the same action from a neutral posture. This leads to earlier onset fatigue and, over time, increases the musculoskeletal risk. Thus, to promote these neutral postures [47], the workstations were redesigned to match the workbench height with the workers' elbows height (between the range-heights: $914-1066 \mathrm{~mm}$, according to the anthropometric data summarized in Figure 7).

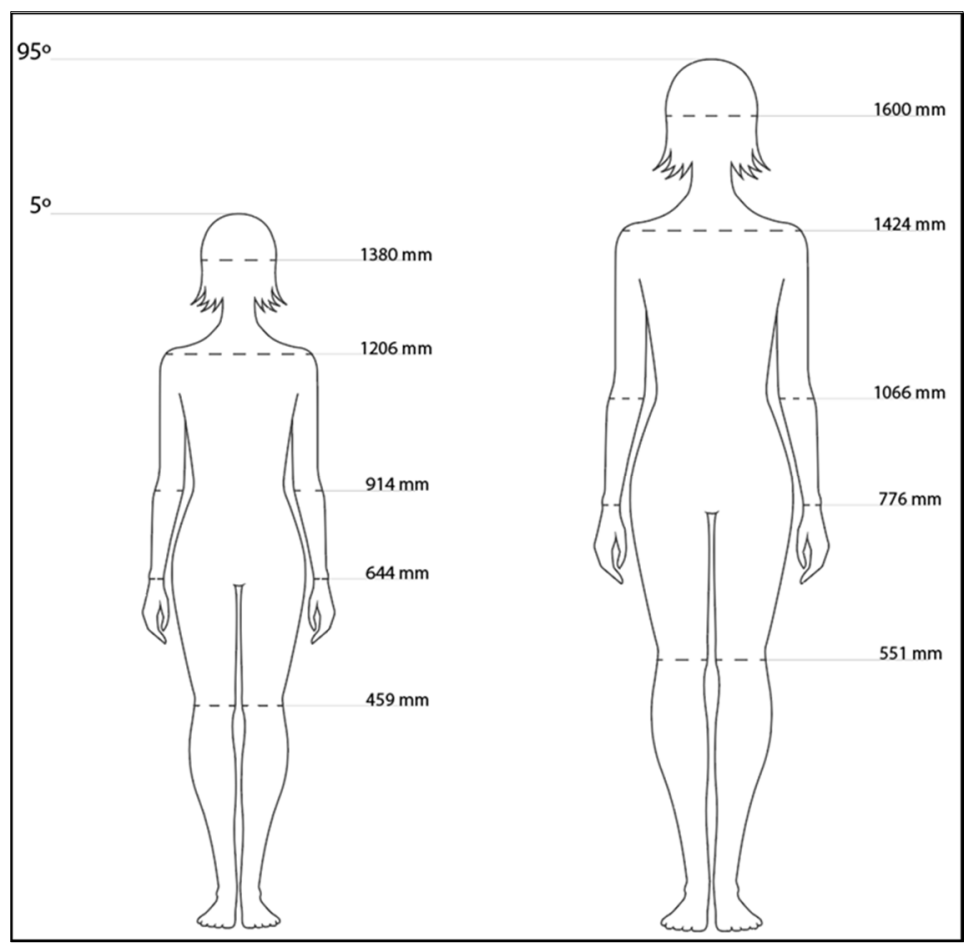

Figure 7. Anthropometric data for the $\mathrm{P}^{\circ}$ and $\mathrm{P}^{\circ} 5^{\circ}$ of the female Portuguese population [29] (expressed in $\mathrm{mm}$, with footwear correction included).

The results obtained point towards a set of requirements for task allocation and conceptual design of the collaborative robotics workstation.

Succinctly, the ergonomic requirements to highlight are:

(i) Eliminate the glue application task. Considered a critical task due to the involved physical strain and repetitiveness. On top of that, burns from hot glue are the most prevalent accident;

(ii) Adjust the workstation's dimensions to adapt to the workers' anthropometric variability;

(iii) Diversify the work content through the inclusion of different tasks/breaks (the assembly work is monotonous and repetitive);

(iv) Implement corrective measures to reduce noise exposure, which hinders communication and increases muscular tension.

To test the applicability of the ergonomic requirements, we created a virtual prototype assembly workstation. We used the Jack-Siemens ${ }^{\circledR}$ software to test different workbench heights within the identified $914 \mathrm{~mm}$ to $1066 \mathrm{~mm}$ interval. The software used the RULA metric to evaluate the postures as a function of the workbench height (Figure 8). The most favorable conditions were achieved for a workbench at a height of $940 \mathrm{~mm}$ from the floor. 


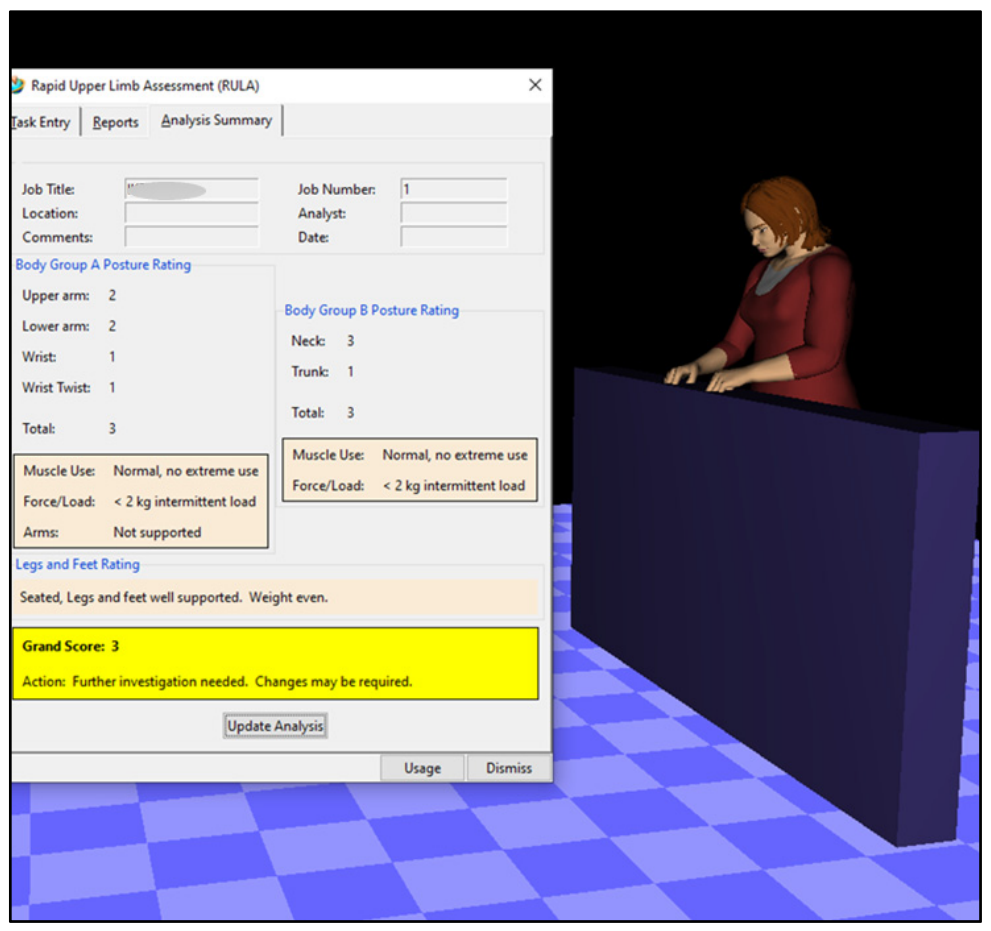

Figure 8. Simulation by Jack—Siemens ${ }^{\circledR}$ trial version and respectively RULA assessment.

Afterward, we created the real workbench prototype (Figure 9). For addressing the ergonomic requirement of eliminating the manual glue application, the robotic workstation will take on the block picking and gluing tasks, dispensing the blocks with glue to the workers. The postures of the wrist-hand system are a concerning risk factor considering the workers' clinical history of carpal tunnel syndrome and the assembly task repetitiveness. To minimize this risk, we tested different block dispenser positions (Table 3), namely:

(i) Above the workbench, dispensing the blocks parallel to the workbench (Condition 1);

(ii) Above the workbench, dispensing the blocks perpendicular to the workbench (Condition 2);

(iii) Below the workbench, dispensing the blocks parallel to the workbench (Condition 3);

(iv) Below the workbench, dispensing the blocks perpendicular to the workbench (Condition 4). 


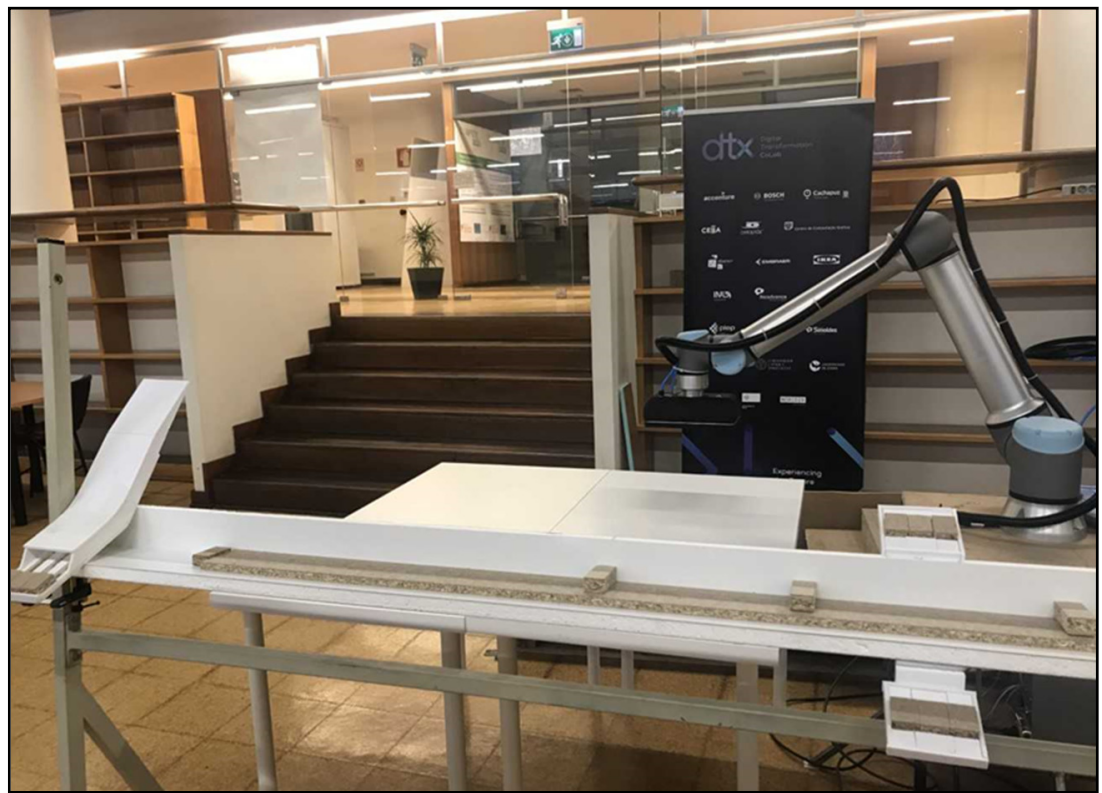

Figure 9. The prototype of the hybrid assembly workstation.

Table 3. Wrist-hand postures across the conditions tested.

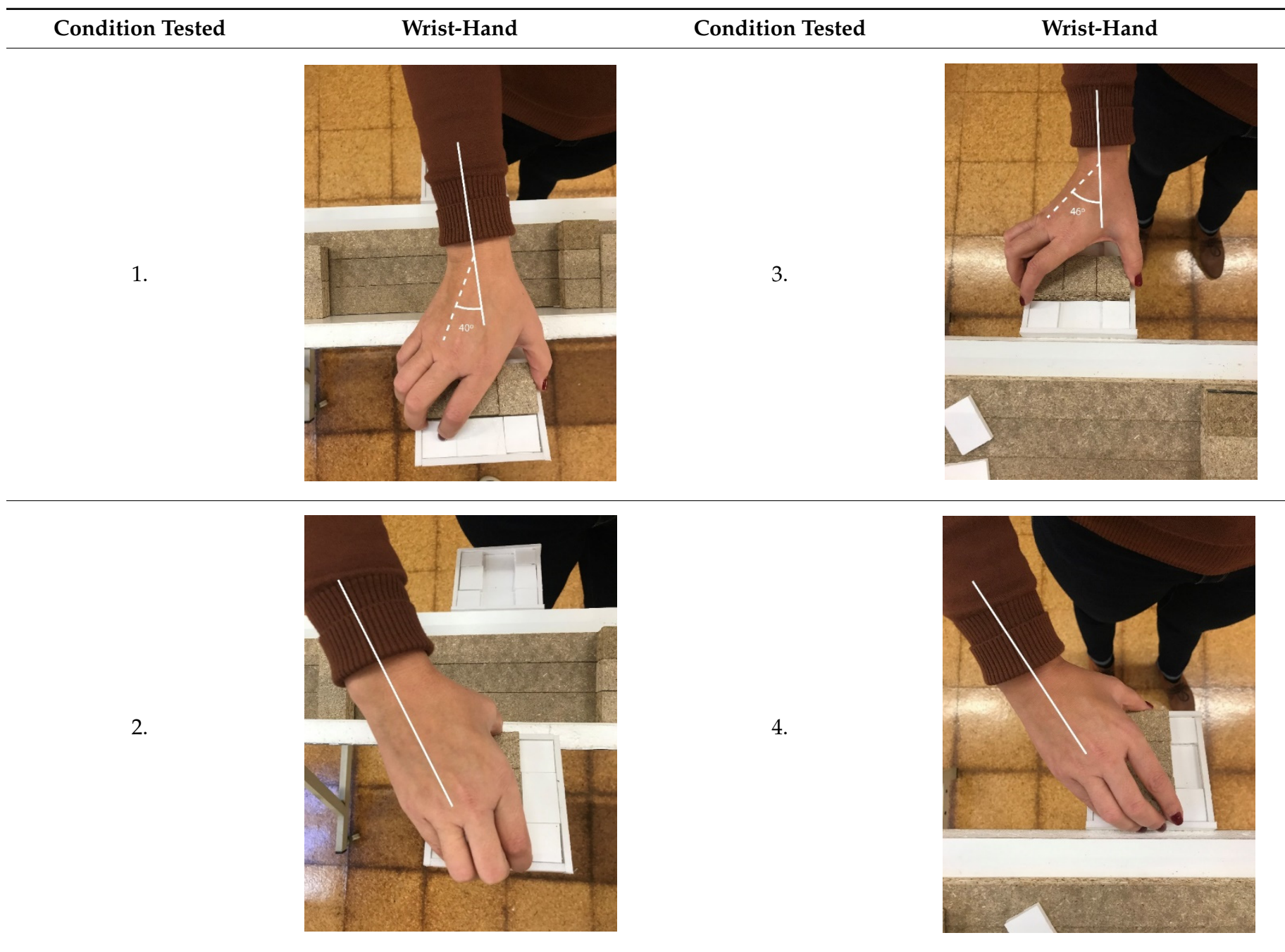


According to the evaluation of the wrist deviation, conditions 1 and 3 increased the lateral deviation (see Table 3). Conditions 2 and 4 reduce the lateral deviation of this joint.

To evaluate the complete work cycle-reaching for and gluing three sets of blocks in the stripes-we applied the XSens ${ }^{\circledR}$ technology (Figure 10).

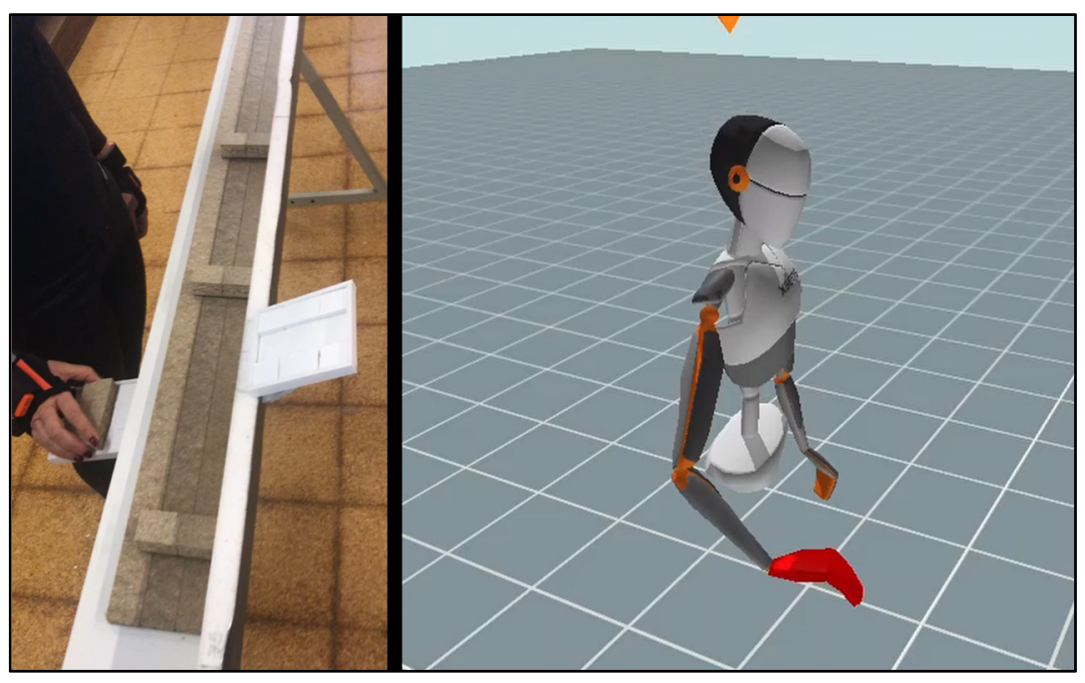

Figure 10. Participant simulating the tasks and the corresponding XSens ${ }^{\circledR}$ output.

The two participants are female and experienced workers in the assembly section (mean age of $34 \pm 2.8$ years old and stature $165 \pm 7.1 \mathrm{~cm}$ ). Table 4 presents the workers' perceptions of the conditions tested. According to these results, condition 2 is the most favorable.

Table 4. Scores related to the discomfort perceived by the workers across the four conditions.

\begin{tabular}{ccc}
\hline Conditions Tested & Worker $\mathbf{1}$ & Worker $\mathbf{2}$ \\
\hline 1. & 2 & 4 \\
2. & 0 & 0 \\
3. & 4 & 5 \\
4. & 6 & 8 \\
\hline
\end{tabular}

When the dispenser was above the workbench, the workers reported unimpeded access to the blocks and the possibility to grasp them with both hands. By enabling bimanual grasping, the workers can vary their postures to prevent musculoskeletal overload.

Regarding the kinematics data collected and its RULA assessment (Figure 11), the simulated tasks present a low risk of developing WMSD, indicating that this workstation redesign is adequate from the ergonomic point of view. To assess the different dispenser conditions, we analyzed the XSens-RULA report for the tracked kinematic frames during a whole cycle. Table 5 presents the final RULA score across the four conditions (including both workers) for the frames related to the block-reaching phase. In this table, the intermediate scores for wrist position and upper arm are highlighted, in order to support the selection of the block dispenser configuration. 


\section{RULA outcome}

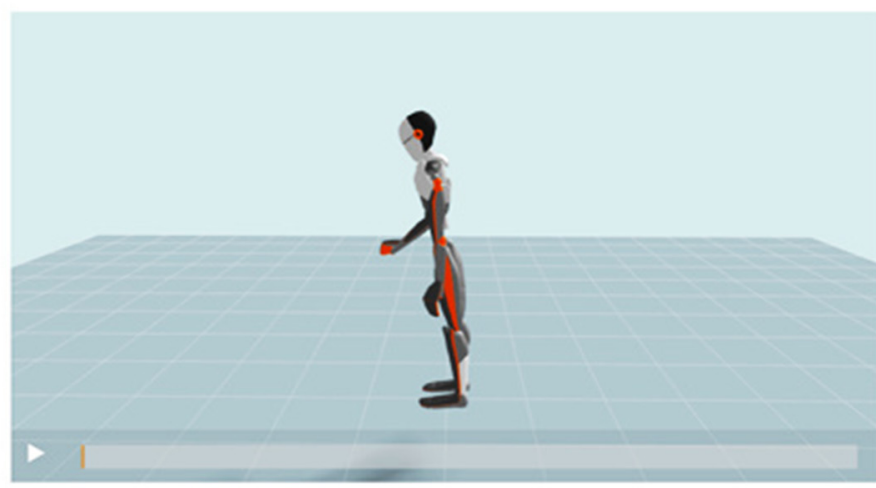

Negligible

Low risk

Medium

Very High

$100 \%$

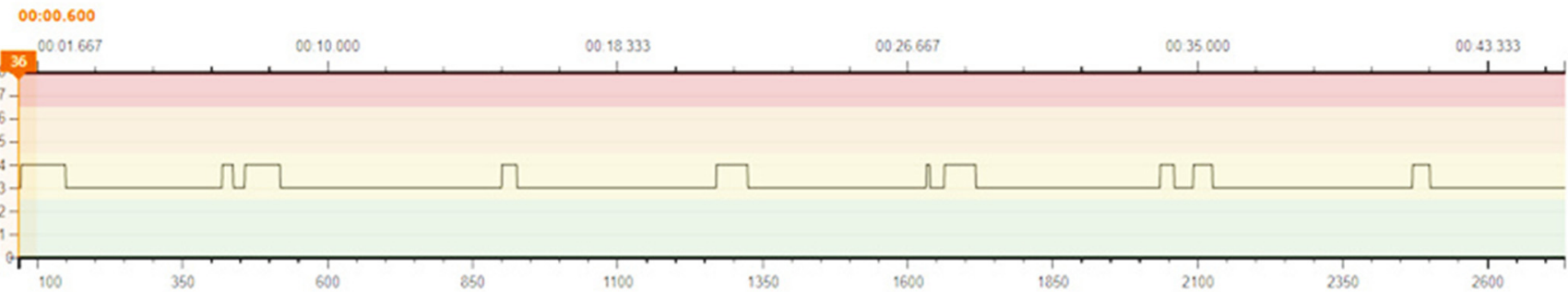

Figure 11. Example of the assessment reported by the XSens-RULA algorithm.

Table 5. Summary of the XSens-RULA assessment for both workers across the conditions tested.

\begin{tabular}{ccccccc}
\hline \multirow{2}{*}{$\begin{array}{c}\text { Conditions } \\
\text { Tested }\end{array}$} & \multicolumn{2}{c}{ Wrist Position Score } & \multicolumn{2}{c}{ Upper Arm Score } & \multicolumn{2}{c}{ Final RULA Score } \\
\cline { 2 - 7 } & W1 & W2 & W1 & W2 & W1 & W2 \\
\hline 1. & 3 & 3 & 4 & 4 & 3 & 4 \\
2. & 2 & 2 & 4 & 3 & 4 & 3 \\
3. & 4 & 3 & 4 & 4 & 3 & 4 \\
4. & 3 & 3 & 4 & 4 & 4 & 4 \\
\hline
\end{tabular}

The results obtained support the previous assumption about the dispenser. These results demonstrate that the lowest scores (best) for the wrist position were obtained for condition 2. Lower RULA scores indicate a lower WMSD risk associated with the evaluated condition $[33,47,48]$.

Globally, the results obtained in this research phase support the workstation redesign, demonstrating that the blocks' dispenser should be placed above the workbench, dispensing the blocks with a perpendicular orientation (Condition 2).

\subsection{Development of Concepts for the Hybrid Workstation}

The integration of a collaborative robot in the assembly workstation addressed the ergonomic requirements (refer to Section 3.2). The future robotic workstation will take on the block picking and gluing tasks. This will reduce the risk inherent to the original workstation. At the same time, the workstation is expected to be designed without safeguards, i.e., with no physical separation between the workspace of the operator and robot.

In order to meet the production requirements, the block picking and gluing tasks need to be supported by automation, guaranteeing that the blocks with glue arrive timely and per worker request. For this particular task, and in order to meet the ergonomics and productivity requirements, the interaction between human and robot will be sequential [9], i.e., the robot will pick a specific set of blocks to pass to each worker using conveyors with 
automatic glue dispensers. During standard operation the workers and cobot workspace is physically separated by a workbench. For material restock, work reference changes and maintenance, the workers must enter the cobot workspace, which is not guarded by safeguards (as represented in Figure 12).

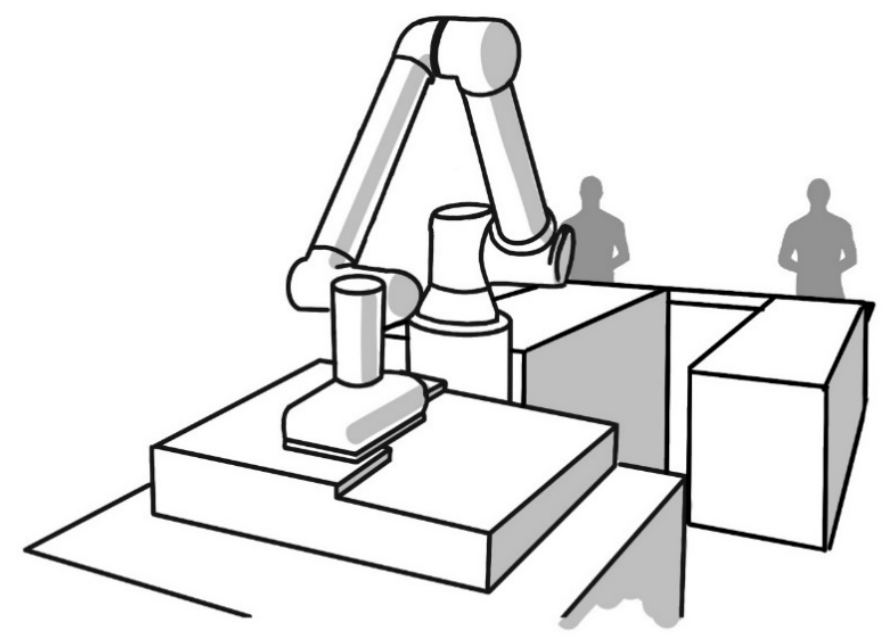

Figure 12. Hybrid workstation conceptualization.

The interaction/contact between human and machine is therefore assumed to be in the PFL operation mode [32]. Following the proposed framework, the design and implementation of the cobot system obeyed the legal directives and was guided by the referred harmonized standards. Upon consulting these documents, several considerations for the robotic system were deliberated to reduce the risk and consequently the required performance level:

(i) The robot selected for the workstation was a collaborative robot-UR10e (Universal Robots A/S, Odense, Denmark). These robots are specifically designed (in accordance with ISO 10218-1 [32]) with no sharp or pointy edges, with a special structure that avoids the risk of entrapment, a built-in torque sensor, and including special safety functions to permit safe interaction with human operators. In terms of task suitability, we sought a cobot with a large reach $(>1100 \mathrm{~mm})$ capable of performing the task at hand, and with at least six degrees-of-freedom in order to reach specific positions and orientations required to manipulate the selected range of references;

(ii) The selection of the gripper that attaches to the robotic arm followed a similar line of thought. The robot by itself is considered a quasi-machine, which passes to the category of the machine as soon as an end-effector is connected. Thus, even if the robot is deemed acceptable for human-robot collaboration, if the attached endeffector introduces severe physical hazards, the robotic application can no longer be recommended for collaborative use. Therefore, the end-effector was selected based on the requirements of the task (need to grasp a combination of wooden blocks, with different dimensions) and based on safe criteria by design-Unigripper ${ }^{\circledR} \mathrm{Co} /$ light (Tepro machine \& Pac System AB, Torsby, Sweden)—a collaborative vacuum endeffector;

(iii) Finally, the glue dispensing unit is covered by a safeguard, eliminating the risk of burns with hot glue. The system relies on high temperatures to melt and project the glue to the blocks. In order to prevent the operator from accessing the heat hazard source, a physical barrier was established in accordance with the distances specified in ISO 13857 [33]. 


\section{Conclusions and Future Work}

The integration of ergonomic principles in the design of a collaborative workstation is a compelling prospect, but one with no straightforward recipe. In this work, we look into an assembly workstation with known physical ergonomic risk and elaborate on the process that drives the design of a new collaborative robotics workstation. We conducted a risk assessment process focused on workers' safety and wellbeing in order to determine the most critical task-applying glue to the blocks.

In this study, we adopted a framework to guide the digital transformation process of repetitive MHO workstations. The applicability of this HRC design methodology extends beyond these task types. By adjusting the physical workload evaluation techniques, this framework can be replicated in other workstations. One of the innovative contributions of this framework is the synthesis of several guidelines present in standards and previous studies, as well as the integration of different criteria and ergonomic evaluation techniques across the design phase. Moreover, the current study constitutes an important contribution for a real-industry development of HRC, focused on a human-centered design.

The drawn conclusions, together with a set of technical and legal requirements, and with the assessment performed in the laboratory prototype, assisted the concept design of the collaborative robotics application. In future work, the new work system with humanrobot task assignment will be implemented on the work floor, involving all stakeholders, especially the workers, in order to achieve an optimal solution that integrates the workers' skills and limitations, as well as the production demands. During the HRC implementation in the factory, ergonomic assessment will be developed, foreseeing the workstation validation to the initial purpose (physical ergonomic improvement), as well as considering workers' perceptions in terms of cognitive ergonomics (as suggested by Chacón et al. [49]). The impact on workers and the overall organizational performance of the assembly section will also be assessed.

Author Contributions: A.C.: conceptualization, methodology, investigation, writing and validation; C.F.: methodology, investigation, writing and validation; J.C.: investigation and writing; J.O.: investigation; N.S.: investigation support; L.A.R.: project supervision. All authors have read and agreed to the published version of the manuscript.

Funding: This work has been supported by NORTE-06-3559-FSE-000018, integrated in the invitation NORTE-59-2018-41, aiming the Hiring of Highly Qualified Human Resources, co-financed by the Regional Operational Programme of the North 2020, thematic area of Competitiveness and Employment, through the European Social Fund (ESF).

Institutional Review Board Statement: The study was conducted according to the guidelines of the Declaration of Helsinki, and approved by the Committee of Ethics for Research in Social and Humans Sciences of the University of Minho (approval number CEICSH 095/2019).

Informed Consent Statement: Informed consent was obtained from all subjects involved in the study.

Data Availability Statement: The data presented in this study are available on request from the corresponding author. The data are not publicly available due to privacy.

Conflicts of Interest: The authors declare no conflict of interest. The funders had no role in the design of the study; in the collection, analyses, or interpretation of data; in the writing of the manuscript, or in the decision to publish the results.

\section{References}

1. Colim, A.; Sousa, N.; Carneiro, P.; Costa, N.; Arezes, P.; Cardoso, A. Ergonomic Intervention on a Packing Workstation with Robotic Aid-Case Study at a Furniture Manufacturing Industry. Work 2020, 66, 229-237. [CrossRef]

2. de Guimarães, L.B.M.; Anzanello, M.J.; Ribeiro, J.L.D.; Saurin, T.A. Participatory Ergonomics Intervention for Improving Human and Production Outcomes of a Brazilian Furniture Company. Int. J. Ind. Ergon. 2015, 49, 97-107. [CrossRef]

3. Bogataj, D.; Battini, D.; Calzavara, M.; Persona, A. The Ageing Workforce Challenge: Investments in Collaborative Robots or Contribution to Pension Schemes, from the Multi-Echelon Perspective. Int. J. Prod. Econ. 2019, 210, 97-106. [CrossRef] 
4. Cherubini, A.; Passama, R.; Crosnier, A.; Lasnier, A.; Fraisse, P. Collaborative Manufacturing with Physical Human-Robot Interaction. Robot. Comput. Integr. Manuf. 2016, 40, 1-13. [CrossRef]

5. Kim, W.; Lorenzini, M.; Balatti, P.; Nguyen, P.; Pattacini, U.; Tikhanoff, V.; Peternel, L.; Fantacci, C.; Natale, L.; Metta, G.; et al. Adaptable Workstations for Human-Robot Collaboration: A Reconfigurable Framework for Improving Worker Ergonomics and Productivity. IEEE Robot. Autom. Mag. 2019, 26, 14-26. [CrossRef]

6. El Zaatari, S.; Marei, M.; Li, W.; Usman, Z. Cobot Programming for Collaborative Industrial Tasks: An Overview. Rob. Auton. Syst. 2019, 116, 162-180. [CrossRef]

7. Villani, V.; Sabattini, L.; Czerniak, J.; Mertens, A.; Vogel-Heuser, B.; Fantuzzi, C. Towards Modern Inclusive Factories: A Methodology for the Development of Smart Adaptive Human-Machine Interfaces. In Proceedings of the 2017 22nd IEEE International Conference on Emerging Technologies and Factory Automation (ETFA), Limassol, Cyprus, 12-15 September 2017; pp. 1-7. [CrossRef]

8. Scholtz, J. Theory and Evaluation of Human Robot Interactions. In Proceedings of the 36th Annual Hawaii International Conference on System Sciences, Big Island, HI, USA, 6-9 January 2003; IEEE: Piscataway Township, NJ, USA, 2003 ; p. 10.

9. Cesta, A.; Orlandini, A.; Bernardi, G.; Umbrico, A. Towards a Planning-Based Framework for Symbiotic Human-Robot Collaboration. In Proceedings of the 2016 IEEE 21st International Conference on Emerging Technologies and Factory Automation (ETFA), Berlin, Germany, 6-9 September 2016; pp. 1-8. [CrossRef]

10. Bicho, E.; Louro, L.; Erlhagen, W. Integrating Verbal and Nonverbal Communication in a Dynamic Neural Field Architecture for Human-Robot Interaction. Front. Neurorobot. 2010, 4, 1-13. [CrossRef]

11. Tan, J.T.C.; Duan, F.; Zhang, Y.; Watanabe, K.; Kato, R.; Arai, T. Human-Robot Collaboration in Cellular Manufacturing: Design and Development. In Proceedings of the 2009 IEEE/RSJ International Conference on Intelligent Robots and Systems, St. Louis, MO, USA, 10-15 October 2009; pp. 29-34. [CrossRef]

12. International Organization for Standardization. ISO/TS 15066 Robots and Robotic Devices—Collaborative Robots; ISO Copyright Office: Geneva, Switzerland, 2016; pp. 1-40.

13. International Electrotechnical Commission. IEC 31010:2019 Risk Management—Risk Assessment Techniques; ISO Copyright Office: Geneva, Switzerland, 2019; pp. 1-264.

14. International Organization for Standardization. ISO/TR 12295:2014 Ergonomics-Application Document for International Standards on Manual Handling (ISO 11228-1, ISO 11228-2 and ISO 11228-3) and Evaluation of Static Working Postures (ISO 11226); ISO Copyright Office: Geneva, Switzerland, 2014; pp. 1-58.

15. International Organization for Standardization. ISO 14738:2002 Safety of Machinery—Anthropometric Requirements for the Design of Workstations at Machinery; ISO Copyright Office: Geneva, Switzerland, 2002; pp. 1-26.

16. Frank, A.; Dalenogare, L.; Ayala, N. Industry 4. 0 Technologies: Implementation Patterns in Manufacturing Companies. Intern. J. Prod. Econ. 2019, 210, 15-26. [CrossRef]

17. Gualtieri, L.; Rauch, E.; Vidoni, R. Emerging Research Fields in Safety and Ergonomics in Industrial Collaborative Robotics: A Systematic Literature Review. Robot. Comput. Integr. Manuf. 2021, 67, 101998. [CrossRef]

18. Neumann, W.P.; Winkelhaus, S.; Grosse, E.H.; Glock, C.H. Industry 4.0 and the Human Factor-A Systems Framework and Analysis Methodology for Successful Development. Int. J. Prod. Econ. 2020, 20, 30341-30348. [CrossRef]

19. Costa Mateus, J.E.; Aghezzaf, E.H.; Claeys, D.; Limère, V.; Cottyn, J. Method for Transition from Manual Assembly to HumanRobot Collaborative Assembly. IFAC-PapersOnLine 2018, 51, 405-410. [CrossRef]

20. Heydaryan, S.; Bedolla, J.S.; Belingardi, G. Safety Design and Development of a Human-Robot Collaboration Assembly Process in the Automotive Industry. Appl. Sci. 2018, 8, 344. [CrossRef]

21. International Organization for Standardization. ISO 31000:2018 Risk Management_Guidelines; ISO Copyright Office: Geneva, Switzerland, 2018; pp. 1-16.

22. Fine, W.T. Mathematical Evaluations for Controlling Hazards; Naval Ordnance Laboratory: White Oak, MD, USA, 1971.

23. Garg, A.; Moore, J.S.; Kapellusch, J.M. The Revised Strain Index: An Improved Upper Extremity Exposure Assessment Model. Ergonomics 2017, 60, 912-922. [CrossRef]

24. Garg, A.; Kapellusch, J.; Hegmann, K.; Wertsch, J.; Merryweather, A.; Deckow-Schaefer, G.; Malloy, E.J. The Strain Index (SI) and Threshold Limit Value (TLV) for Hand Activity Level (HAL): Risk of Carpal Tunnel Syndrome (CTS) in a Prospective Cohort. Ergonomics 2012, 55, 396-414. [CrossRef]

25. Borg, G. Psychophysical Scaling with Applications in Physical Work and the Perception of Exertion. Scand. J. Work. Environ. Heal. 1990, 16 (Suppl. 1), 55-58. [CrossRef]

26. Plamondon, A.; Larivière, C.; Denis, D.; Mecheri, H.; Nastasia, I. Difference between Male and Female Workers Lifting the Same Relative Load When Palletizing Boxes. Appl. Ergon. 2017, 60, 93-102. [CrossRef] [PubMed]

27. Shariat, A.; Cleland, J.A.; Danaee, M.; Alizadeh, R.; Sangelaji, B.; Kargarfard, M.; Ansari, N.N.; Sepehr, F.H.; Tamrin, S.B.M. Borg CR-10 Scale as a New Approach to Monitoring Office Exercise Training. Work 2018, 60, 549-554. [CrossRef] [PubMed]

28. International Organization for Standardization. ISO 9241-210:2010 Ergonomics of Human-System Interaction-Part 210: HumanCentred Design for Interactive Systems; ISO Copyright Office: Geneva, Switzerland, 2010.

29. Barroso, M.P.; Arezes, P.M.; Da Costa, L.G.; Miguel, A.S. Anthropometric Study of Portuguese Workers. Int. J. Ind. Ergon. 2005, 35, 401-410. [CrossRef] 
30. The European Parliament and the Council of the European Union. Machinery Directive 2006/42/EC; Publications Office of The EU: Luxembourg, 2006; Volume 16, pp. 24-86.

31. Faria, C.; Colim, A.; Cunha, J.; Oliveira, J.; Costa, N.; Carneiro, P.; Monteiro, S.; Bicho, E.; Rocha, L.A.; Arezes, P. Safety Requirements for the Design of Collaborative Robotic Workstations in Europe-A Review. In Advances in Intelligent Systems and Computing; Springer: Cham, Switzerland, 2020; Volume 1204 AISC, pp. 225-232. ISBN 9783030509453.

32. International Organization for Standardization. ISO 10218 Robots and Robotic Devices—Safety Requirements for Industrial RobotsPart 2: Robot Systems and Integration; ISO Copyright Office: Geneva, Switzerland, 2011; pp. 1-80.

33. International Organization for Standardization. ISO 13857:2019 Safety of Machinery—Safety Distances to Prevent Hazard Zones Being Reached by Upper and Lower Limbs; ISO Copyright Office: Geneva, Switzerland, 2019; pp. 1-20.

34. Siemens. Siemens Jack 2019. Available online: https://www.dex.siemens.com/plm/tecnomatix/process-simulate-human (accessed on 21 September 2020).

35. McAtamney, L.; Corlett, N. RULA: A Survey Method for the Investigation of Work-Related Upper Limb Disorders. Appl. Ergon. 1993, 24, 91-99. [CrossRef]

36. Chiasson, M.; Imbeau, D.; Aubry, K.; Delisle, A. Comparing the Results of Eight Methods Used to Evaluate Risk Factors Associated with Musculoskeletal Disorders. Int. J. Ind. Ergon. 2012, 42, 478-488. [CrossRef]

37. Vignais, N.; Miezal, M.; Bleser, G.; Mura, K.; Gorecky, D.; Marin, F. Innovative System for Real-Time Ergonomic Feedback in Industrial Manufacturing. Appl. Ergon. 2013, 44, 566-574. [CrossRef]

38. Garg, A.; Kapellusch, J.M. Job Analysis Techniques for Distal Upper Extremity Disorders. Rev. Hum. Factors Ergon. 2011, 7, 149-196. [CrossRef]

39. Merino, G.; da Silva, L.; Mattos, D.; Guimarães, B.; Merino, E. Ergonomic Evaluation of the Musculoskeletal Risks in a Banana Harvesting Activity through Qualitative and Quantitative Measures, with Emphasis on Motion Capture (Xsens) and EMG. Int. J. Ind. Ergon. 2019, 69, 80-89. [CrossRef]

40. Saber-sheikh, K.; Bryant, E.C.; Glazzard, C.; Hamel, A.; Lee, R.Y.W. Feasibility of Using Inertial Sensors to Assess Human Movement. Man. Ther. 2010, 15, 122-125. [CrossRef]

41. Zhang, J.; Novak, A.C.; Brouwer, B. Concurrent Validation of Xsens MVN Measurement of Lower Limb Joint Angular Kinematics Concurrent Validation of Xsens MVN Measurement of Lower Limb Joint Angular Kinematics. Physiol. Meas. 2013, 34 , N63. [CrossRef] [PubMed]

42. Morata, T.C.; Fiorini, A.C.; Fischer, F.M.; Krieg, E.F.; Gozzoli, L.; Colacioppo, S. Factors Affecting the Use of Hearing Protectors in a Population of Printing Workers. Noise Heal. 2001, 4, 25-32.

43. Nélisse, H.; Gaudreau, M.A.; Boutin, J.; Voix, J.; Laville, F. Measurement of Hearing Protection Devices Performance in the Workplace during Full-Shift Working Operations. Ann. Occup. Hyg. 2012, 56, 221-232. [CrossRef] [PubMed]

44. International Organization for Standardization. ISO 6385:2016 Ergonomics Principles in the Design of Work Systems; ISO Copyright Office: Geneva, Switzerland, 2016; pp. 1-15.

45. Gualtieri, L.; Palomba, I.; Merati, F.A.; Rauch, E.; Vidoni, R. Design of Human-Centered Collaborative Assembly Workstations for the Improvement of Operators' Physical Ergonomics and Production Efficiency: A Case Study. Sustainability 2020, $12,3606$. [CrossRef]

46. Antonucci, A. Comparative Analysis of Three Methods of Risk Assessment for Repetitive Movements of the Upper Limbs: OCRA Index, ACGIH(TLV), and Strain Index. Int. J. Ind. Ergon. 2019, 70, 9-21. [CrossRef]

47. Moore, S.M.; Torma-Krajewski, J.; Steiner, L.J. Practical Demonstrations of Ergonomic Principles; National Institute for Occupational Safety and Health Publications: Pittsburgh, PA, USA, 2011.

48. Kushwaha, D.K.; Kane, P.V. Ergonomic Assessment and Workstation Design of Shipping Crane Cabin in Steel Industry. Int. J. Ind. Ergon. 2016, 52, 29-39. [CrossRef]

49. Chacón, A.; Ponsa, P. Applied Sciences On Cognitive Assistant Robots for Reducing Variability in Industrial Human-Robot Activities. Appl. Sci. 2020, 10, 5137. [CrossRef] 